\title{
Alterations to the Blood-Retinal Barrier in Diabetes: Cytokines and Reactive Oxygen Species
}

\author{
Tiffany Frey ${ }^{1}$ and David A. Antonetti ${ }^{2}$
}

\begin{abstract}
Diabetic retinopathy (DR) is a leading cause of blindness in Western society. Since the prevalence of diabetes continues to increase dramatically, the impact of DR will only worsen unless new therapeutic options are developed. Recent data demonstrate that oxidative stress contributes to the pathology of DR and inhibition of oxidative stress reduces retinal vascular permeability. However, direct mechanisms by which oxidative stress alters the blood-retinal barrier (BRB) and increases vascular permeability remain to be elucidated. A large body of evidence demonstrates a clear role for altered expression of cytokines and growth factors in DR, resulting in increased vascular permeability, and the molecular mechanisms for these processes are beginning to emerge. The pathology of DR is likely a result of metabolic dysregulation contributing to both oxidative stress and cytokine production. This review will examine the evidence for oxidative stress, growth factors, and other cytokines in tight junction regulation and vascular permeability in DR. Antioxid Redox Signal. 15, 1271-1284.
\end{abstract}

\section{Introduction}

\section{The Retina}

T HE RETINA IS A TRANSPARENT, MULTI-LAYER TISSUE flanked by the choroid and the vitreous body in the posterior eye. This complex organ is designed to detect light and convert this signal into electrical impulses that are then transmitted via the optic nerve to the brain for interpretation of the image. In primates, the macula, which includes the fovea and foveola, possesses a high density of cones and is more sensitive in bright-light conditions, providing acuity and color perception. The peripheral retina operates in dim-light conditions and functions to detect motion and peripheral vision. Figure 1 provides a fundus photograph of the normal human retina demonstrating the optic nerve head, blood vessels, macula, fovea, and foveola.

A variety of cell types in the retina coordinate their activity to achieve the conversion of light to neural signals. Neurons including photoreceptors, ganglion, bipolar, horizontal, and amacrine cells; macroglia including Müller cells and astrocytes; microglia or resident macrophages; retinal pigment epithelium (RPE), and microvascular cells including both pericytes and endothelial cells (Fig. 2A) all interact to create the light-stimulated neural impulse interpreted by the brain as vision. The neurons are organized in layers creating the outer nuclear layer (ONL) made of rods and cones, the inner nuclear layer (INL) consisting of bipolar, horizontal, and amacrine cells, and the ganglion cell layer (GCL). These neurons make synaptic connections in the outer plexiform layer (OPL) and the inner plexiform layer (IPL) (Fig. 2B). The rods also interact with the RPE as part of the visual cycle to recover rhodopsin after light signal transduction. Müller cells and astrocytes provide nutritional and regulatory support to neurons and integrate vascular and neuronal signals. Microglia are resident macrophages that monitor the local environment and provide immunomodulatory functions. Finally, the inner retinal circulation stems from the central retinal artery, which branches to three capillary plexuses that anastamose across the inner most superficial region of the retina, through the ganglion cell layer, and throughout the inner nuclear layer (113). Diffusion from the choroidal blood vessels across the RPE provides metabolic support for the outer retina.

Similar to the central nervous system (CNS), retinal function depends on cellular communication among neurons and metabolic exchange between neurons and support cells. These interactions require a defined environment that is achieved by the formation of the blood-brain barrier (BBB) and bloodcerebrospinal fluid barrier (BCSFB) in the CNS (23a) and the blood-retinal barrier (BRB), thereby separating neural tissue from the circulation. The RPE contributes to the outer BRB and allows oxygen diffusion from the choroidal circulation to the highly metabolic rods and cones. The inner BRB (iBRB) is formed by the blood vessels in the inner retina. The BRB serves as a selective barrier providing immune privilege and regulating osmotic balance, ionic concentration, and the transport of nutrients (sugars, lipids, and amino acids), thereby helping to control the specialized environment of the retina. In addition,

\footnotetext{
${ }^{1}$ Department of Cellular and Molecular Physiology, Penn State College of Medicine, Hershey, Pennsylvania.

${ }^{2}$ Ophthalmology and Visual Sciences, University of Michigan Kellogg Eye Center, Ann Arbor, Michigan.
} 


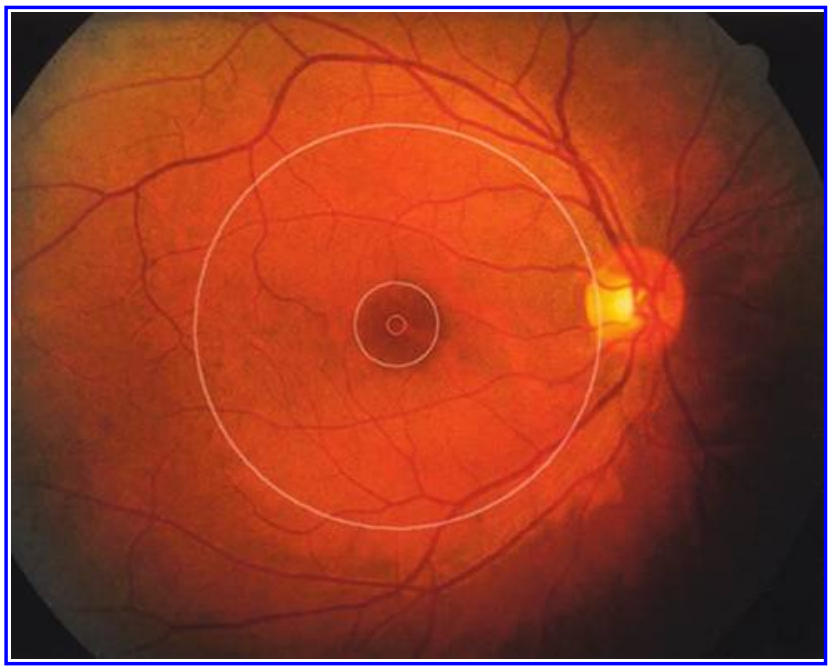

FIG. 1. Fundus photograph of the normal human retina demonstrates the optic nerve head with blood vessels that radiate from the central retinal artery. The macula, fovea, and foveola are shown in consecutively smaller circles. The macula remains avascular since this region and the contained fovea have the highest concentration of cones providing central visual acuity. Macular edema is closely associated with vision loss in DR. Adapted from (6). (To see this illustration in color the reader is referred to the web version of this article at www.liebertonline.com/ars).

pericytes, which are modified smooth muscle cells, share a common basal lamina and directly contact vascular endothelial cells. Formation of the iBRB requires specialized differentiation of the vascular endothelial cells induced by astrocytes, Müller cells, and pericytes (Fig. 3 and reviewed in Ref. 33).

An important component of both the BBB (23a) and BRB is the endothelial tight junction complex. Over 40 proteins have been found to be associated with tight junctions and include transmembrane, scaffolding, and signaling proteins (51). In particular, the transmembrane proteins occludin, tricellulin, the claudin family, and junction adhesion molecules (JAMs), along with the scaffolding zonula occludens proteins ( $\mathrm{ZO}-1$, $-2,-3)$ play major roles in the formation and regulation of the tight junction barrier (14a, 16a, 51a, 89a). Alterations to these proteins contribute to the loss of the blood-retinal barrier in diabetic retinopathy.

\section{Diabetic retinopathy}

Diabetic retinopathy (DR) is a complication of both type 1 and type 2 diabetes and is the leading cause of acquired blindness in people aged 20-74 years in the United States (91). DR is classified as either nonproliferative (NPDR) or proliferative (PDR). Diabetic complications such as retinopathy are often characterized as microvascular disorders but many retinal cells are affected in diabetes (6). However, vascular changes are clearly linked to loss of visual acuity and observed changes to the retinal vasculature direct clinical care. Early vascular changes include leukostasis, aggregation of platelets, altered blood flow, degeneration of pericytes, and basement membrane thickening (33). Increased retinal vascular permeability is a well-established pathology associated with DR (43) and may result from changes in the tight junction and adherens junction complexes or from increased endothelial cell death (Fig. 4). Macular edema is closely associated with loss of visual acuity in DR $(82,47)$ and increased permeability of the BRB is believed to contribute to macular edema $(93,100)$. Therefore, understanding mechanisms of vascular permeability and subsequent macular edema may provide therapeutic options to prevent or reverse loss of retinal function in diabetes.

Hyperglycemia has been proposed to result in the microvascular pathogenesis of DR due to increased alterations in cell signaling pathways, including increased polyol pathway flux,

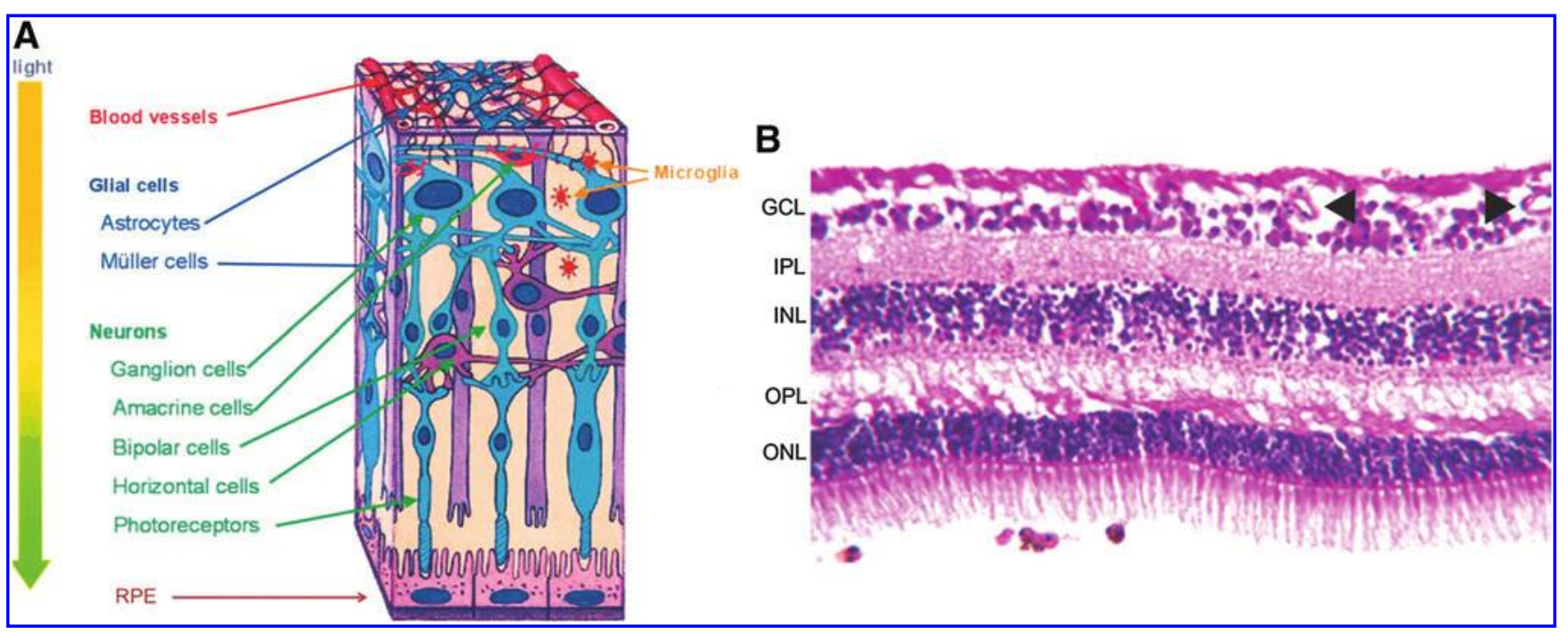

FIG. 2. Schematic of retinal structure (A) and hematoxylin and eosin stain of normal human retina (B). (A) The schematic illustrates neurons, glial cells, microglial cells, retinal pigment epithelia (RPE), and blood vessels. These cells interact to convert light signal to an electrical impulse carried by the ganglion cells to the visual cortex in the brain. Adapted from (6). (B) The stain demonstrates the ganglion cell layer (GCL), inner plexiform layer (IPL), inner nuclear layer (INL), outer plexiform layer (OPL), and outer nuclear layer (ONL). Blood vessels are detectable in the GCL as indicated by the arrowheads. Arterioles and capillary plexuses branching from the central retinal artery support the inner retina, whereas diffusion across the RPE from the choroidal blood vessels (not shown) provides support for the outer retina. (To see this illustration in color the reader is referred to the web version of this article at www.liebertonline.com/ars). 


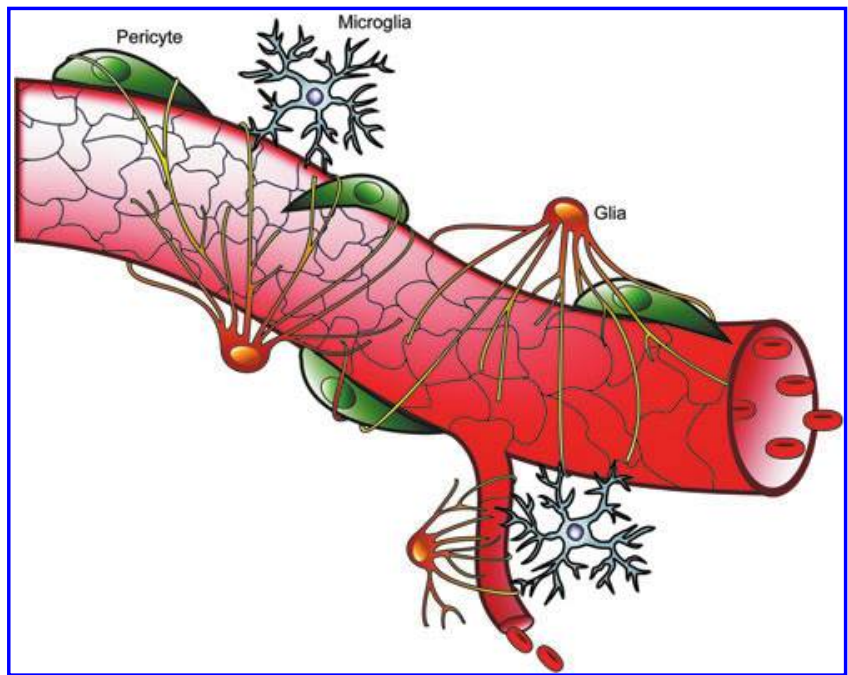

FIG. 3. Components of a healthy BRB. Glial cells (Müller cells and astrocytes) are the interface between neurons and the vasculature providing nutritional and regulatory support for the neurons. Pericytes share a common basal lamina and come into direct contact with endothelial cells. Microglia are resident macrophages that monitor the local environment and provide immunomodulatory functions. Astrocytes, Müller cells, and pericytes are required for the specialized differentiation of endothelial cells needed to form the BRB. This figure is re-published from (33), with permission of Springer Science + Business Media. (To see this illustration in color the reader is referred to the web version of this article at www.liebertonline.com/ars).

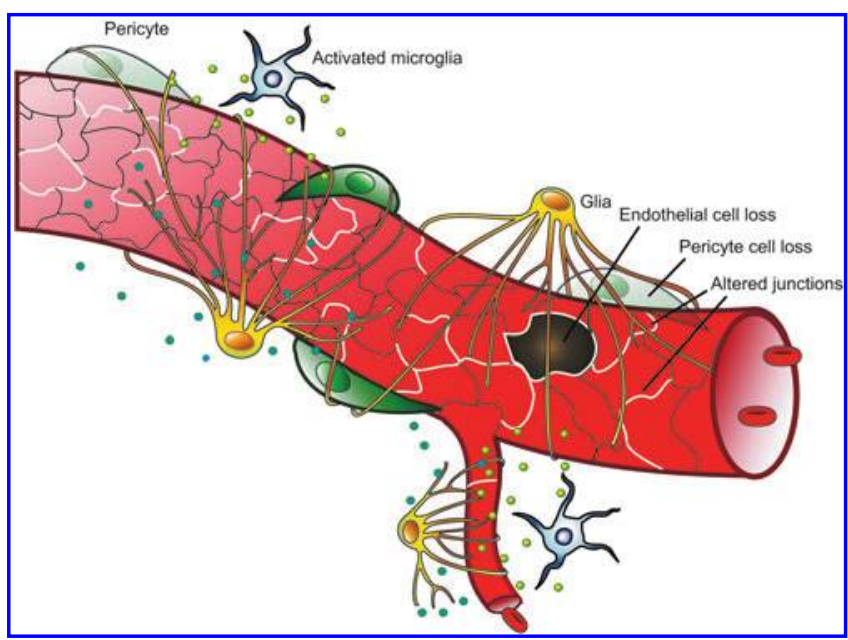

FIG. 4. Disruption of the BRB in diabetic retinopathy. As a result of metabolic dysregulation leading to increased production of growth factors and cytokines (small circles) in DR, the vasculature undergoes a number of changes including increased leukostasis, vascular occlusion, and pericyte loss. A combination of these factors leads to tight junction alterations and cell death of vascular endothelial cells, resulting in increased vascular permeability and subsequent macular edema. This figure is re-published from (33), with permission of Springer Science+ Business Media. (To see this illustration in color the reader is referred to the web version of this article at www.liebertonline.com/ars). increased advanced glycation end-product (AGE) formation, activation of protein kinase $\mathrm{C}$ (PKC) isoforms, and increased hexosamine pathway flux (18). Alternatively, diabetes induces expression of growth factors and inflammatory cytokines in the retina that are the target of multiple phase 3 clinical trials (reviewed in Ref. 46). This review will consider the evidence for the direct effect of hyperglycemia-induced reactive oxygen species (ROS) production and subsequent vascular damage in the diabetic retina and also examine the data suggesting that metabolic dysregulation in diabetes results in cytokine production that alters the BRB and induces vascular permeability. The final section will consider how these two hypotheses may both contribute to the observed disease etiology.

\section{Oxidative Stress and ROS in Diabetic Retinopathy}

The term oxidative stress has been used to define a number of different processes that are altered in DR. In this review we will refer to oxidative stress as a prolonged or persistent alteration in the NADH $(\mathrm{NADPH}) / \mathrm{NAD}^{+}\left(\mathrm{NADP}^{+}\right)$ratios, while ROS refers to production of reactive oxygen species. Changes in oxidative stress may impact cell processes by a number of mechanisms. Importantly, loss of NADPH can reduce the activity of glutathione reductase, an enzyme necessary to maintain the intracellular pool of reduced glutathione (GSH). GSH plays a central role in detoxification by reducing hydrogen peroxide, so alterations in $\mathrm{NADPH} / \mathrm{NADP}^{+}$ratio may lessen the ability of cells to respond to ROS (13). There are many potential sources of oxidative stress and ROS production in the diabetic retina, including increased polyol pathway flux, altered mitochondrial metabolism, increased NADPH or xanthine oxidase activity, and the increased formation of reactive nitrogen oxide species (RNOS) such as peroxynitrite (Fig. 5). ROS can oxidize cellular macromolecules, resulting in altered function and contribution to disease pathogenesis. The evidence examining a role for each of these sources of oxidative stress and ROS in models of diabetes, as well as in endothelial cells treated with high glucose, will be examined.

\section{Polyol pathway}

Excess intracellular glucose may be metabolized in the polyol pathway (35) with evidence for increasing flux through this pathway in the diabetic rat retina (89). Aldose reductase (AR) first reduces glucose to sorbitol using NADPH as a cofactor, potentially limiting the availability of NADPH for glutathione reductase. The sorbitol is then oxidized to fructose with the corresponding reduction of $\mathrm{NAD}+$ to NADH (Fig. 5). This has been reported to result in an increased NADH/NAD + ratio that mimics hypoxia (due to impaired oxidation of NADH to NAD +) and has been referred to as hyperglycemic pseudohypoxia (107). The excess NADH may become a substrate for NADH oxidase leading to production of ROS (72). In support of the hyperglycemic pseudohypoxia hypothesis, exposure of retinas from normal rats to high glucose concentrations (20 and $30 \mathrm{mM}$ ) for only 2 hours induced a hypoxia-like increase in the lactate-to-pyruvate ratio (indicative of an increased ratio of NADH/NAD+ ) $(85,103)$.

A number of preclinical studies support a role for the polyol pathway in the pathology of DR. The accumulation of sorbitol and fructose has been correlated with changes in the activation state of astrocyte and Müller glial cells as measured by 


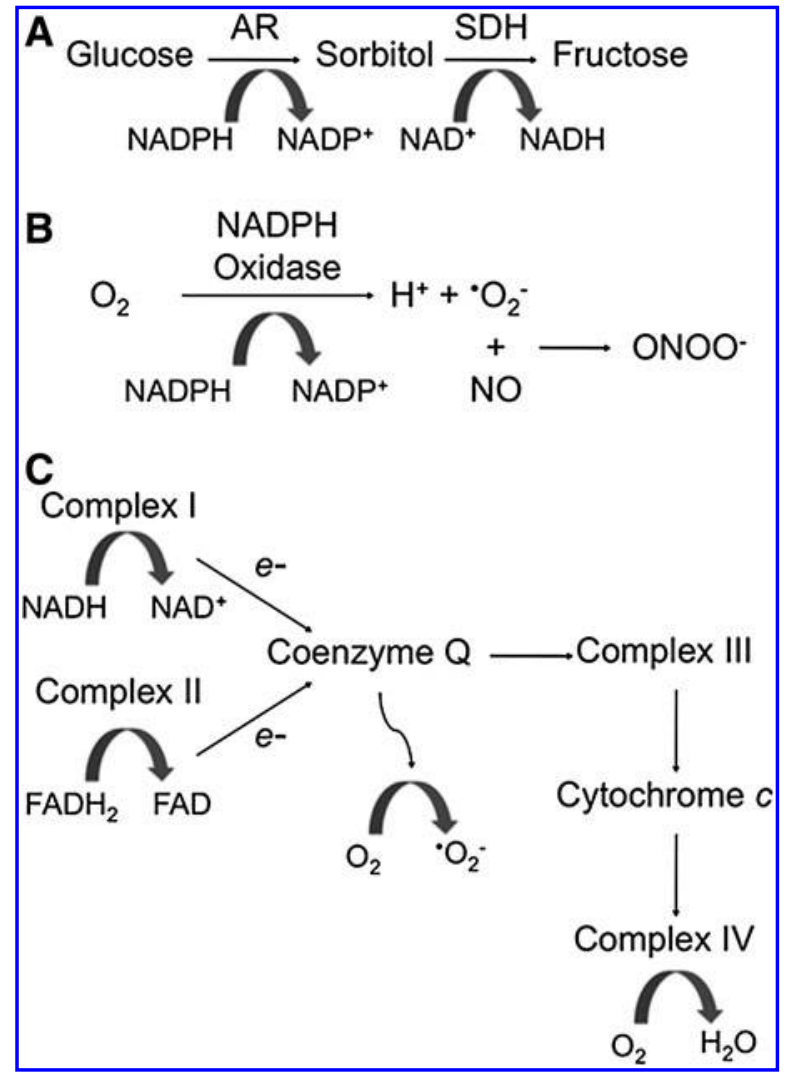

FIG. 5. Sources of oxidative stress and ROS in diabetic retinopathy. Excess glucose has the potential to activate the polyol pathway whereby glucose is converted to sorbitol by aldose reductase (AR) and then to fructose by sorbitol dehydrogenase $(\mathrm{SDH})$. These reactions result in the depletion of $\mathrm{NADPH}$ and an increase in the $\mathrm{NADH} / \mathrm{NAD}^{+}$ratio, resulting in oxidative stress (A). DR leads to increased NADPH oxidase activity, resulting in increased production of superoxide. Superoxide can react with NO to form the RNOS peroxynitrite (B). Alterations in the mitochondrial electron transport chain can also result in the production of ROS in diabetes. Electrons from $\mathrm{NADH}$ and $\mathrm{FADH}_{2}$ are donated to complex I and complex II, respectively. Complexes I and II then donate electrons to coenzyme $Q$, which donates electrons to complex III followed by cytochrome c and finally complex IV. Alterations in electron transport can cause coenzyme $Q$ to donate electrons to molecular oxygen, resulting in the production of mitochondrial superoxide $(\mathrm{C})$.

immunoreactivity of glial fibrillary acidic protein (GFAP) and an increase in the number of apoptotic neurons. These effects were prevented with the aldose reductase inhibitor (ARI) sorbinil (9). Increased retinal lipid peroxidation and vascular endothelial growth factor (VEGF) protein expression in diabetic rats as well as increased ROS production in highglucose-treated bovine retinal endothelial cells (BREC) were prevented by the ARI fidarestat (86). ARIs have also been shown to prevent vascular permeability changes (101) and retinal basement membrane thickening (20) in diabetic rats. In addition, sorbinil treatment of diabetic rats prevented both microvascular cell apoptosis and the formation of acellular capillaries, a morphological measure believed to be related to pericyte apoptosis (25). The ARI fidarestat diminished the prevalence of microaneurysms, basement membrane thick- ening, and pericyte loss in the retinas of diabetic rats in a dosedependent manner (63). In bovine retinal pericyte cell culture, the ARI SNK-860 prevented high-glucose induced apoptosis and decreased GSH content (78).

Data from AR deficient mice also support a role for the polyol pathway in DR. In mice, AR expression was localized to astrocytes, Müller cells, retinal ganglion cells, and the neurons of the INL. In the blood vessels, AR staining was visualized in the pericytes, but not the endothelial cells. The intensity of staining was increased in the $\mathrm{db} / \mathrm{db}$ mouse model of type II diabetes, suggesting an increase in expression of $\mathrm{AR}$ in the retina of diabetic mice. In AR-deficient mice, a number of diabetes-induced pathologies were normalized as compared to AR-expressing diabetic mice, including pericyte loss, vascular leakage, oxidative-nitrosative stress, VEGF expression, glial cell reactivity, neuronal cell apoptosis, and neovascularization (23).

In contrast to the above results, Winkler et al. found that the content of ATP and lactate in retinas did not differ between fresh tissue and tissue incubated in high glucose (108). Later work revealed no differences in either the NADH/NAD + or lactate/pyruvate ratios between control and diabetic rat retinas and once again, no differences in lactate or pyruvate levels were observed between fresh retinas and those incubated in media containing high glucose (29). In a study by Ola et al., the lactate/pyruvate ratio was actually found to decrease in rat retinas with increasing duration of diabetes, but this same study found increased flux through the polyol pathway with increasing duration of diabetes, suggesting that depletion of NADPH may make a contribution to oxidative stress in the retina of the diabetic rat (89). Finally, a clinical research trial using sorbinil was not effective in the treatment of retinopathy (1). In summary, there remains uncertainty about the contribution of the polyol pathway to the pathology of DR and in particular loss of the BRB.

\section{Mitochondria}

The metabolism of glucose by the tricarboxylic acid (TCA) cycle generates the electron donors $\mathrm{NADH}$ and $\mathrm{FADH}_{2}$, which donate electrons to the mitochondrial electron transport chain. The electron transport chain utilizes a series of redox reactions to pump protons across the inner mitochondrial membrane, resulting in a voltage gradient used to drive the synthesis of ATP. Oxygen is the final electron acceptor and thus respiration yields $\mathrm{H}_{2} \mathrm{O}$ production. While the electron transport chain is essential for energy metabolism, the system has also been implicated in production of ROS due to incomplete and premature reduction of oxygen to form free radicals (Fig. 5).

In 1996, Giardino et al. suggested that hyperglycemia can result in the production of ROS in cultured bovine aortic endothelial cells (BAEC) (50). This work was followed in 2000 by Nishikawa et al. (84), who demonstrated that the hyperglycemia-induced increase in ROS could be prevented by blocking the electron transport chain function with either an inhibitor of electron transport chain complex II, an uncoupler of oxidative phosphorylation, or by overexpression of uncoupling protein-1 (UCP-1). Uncoupling proteins can relieve the proton gradient without ATP generation and thereby regulate ATP production. In addition, overexpression of the mitochondrial ROS scavenger, manganese superoxide dis- 
mutase (MnSOD) blocked ROS production. These studies linked hyperglycemia-induced ROS production in BAEC to mitochondrial function (84). This group further demonstrated that normalizing levels of mitochondrial ROS prevented glucose-mediated activation of protein kinase C (PKC), formation of advanced glycation end products (AGEs), and sorbitol accumulation from the polyol pathway, which are three key factors in the pathogenesis of diabetes (84).

Hyperglycemia was subsequently shown to activate a fourth contributor to the pathogenesis of diabetes, the hexosamine biosynthetic pathway, via mitochondrial superoxide production in BAEC (31). Furthermore, through the use of JC-1, a dye that is responsive to increasing mitochondrial membrane potential, and the use of digital imaging, it was demonstrated that hyperglycemia increased the mitochondrial proton electrochemical gradient in BAEC and that overexpression of UCP-1 was able to restore the gradient to normal (30). This accumulation of evidence resulted in the proposal by Brownlee that the single event of increased superoxide production by the mitochondrial electron transport chain results in four important molecular mechanisms implicated in glucose-mediated vascular damage (18).

Mitochondrial generation of ROS may contribute to retinal pathology in DR. Scavenging ROS by administration of the thiol antioxidant, alpha-lipoic acid for the entire duration of diabetes in rats inhibited capillary cell apoptosis, reduced the number of acellular capillaries, and reduced oxidative damage to DNA (8-hydroxy guanosine levels) and proteins (nitrotyrosine) in the retina as compared to nontreated rats after 11 months of diabetes (68). In support of a role for production of ROS in this pathology, MnSOD mRNA expression and activity were reduced in the retinas of diabetic rats, an effect that was prevented by long-term treatment with lipoic acid (65). Overexpression of human MnSOD under the $\beta$-actin promoter was achieved in mice with an increase in retinal MnSOD protein and enzyme activity levels of $60 \%$ and $70 \%$, respectively. These mice were protected from diabetesinduced oxidative stress as observed by decreased oxidative damage to DNA and proteins (67). Furthermore, mitochondria isolated from diabetic mouse retina had increased superoxide levels and decreased activity of complex III. Overexpression of MnSOD attenuated both of these effects and blocked the increased formation of acellular capillaries in diabetic mice (62). In addition, overexpression of MnSOD prevented apoptosis and oxidative damage to DNA and proteins in high-glucose-treated BREC, indicating that the in vivo observations could at least in part be due to a direct effect on microvascular endothelial cells (65). Cui et al. also observed high glucose induced increase in mitochondrial membrane potential and ROS production in BREC (24). In addition, the hyperglycemia-induced increase in the mitochondrial membrane potential was blocked by the angiotensin-converting enzyme inhibitor perindopril through upregulation of peroxisome proliferator-activated receptor $\gamma$ (PPAR $\gamma$ ) and subsequent UCP-2 expression (114). However, caution must be used when interpreting the cell culture hyperglycemia data in relation to the diabetic retina. Cell culture experiments are carried out with isolated cells and over a time course of hours to days while diabetic animals have a complex metabolic derangement including hyperglycemia for weeks to months.

The above studies suggest that increased ROS production in diabetes is the result of an increase in the mitochondrial membrane potential. However, in a study utilizing human retinal endothelial cells (HREC), oxidative damage of mitochondrial DNA (mtDNA) was observed only 3 hours after high glucose treatment closely followed by decreased expression of mtDNA encoded respiratory chain subunits and decreased mitochondrial membrane potential. Increased mitochondrial ROS production began 12 hours after the start of high glucose treatment, followed by apoptosis at 24 hours. This series of events suggests that oxidative damage of mtDNA is the initiating event in hyperglycemia-induced mitochondrial ROS production and, in contrast to the studies outlined above, is the result of a decrease in mitochondrial membrane potential due to decreased expression of respiration chain subunits (109). Further, high glucose treatment of $e x$ vivo retinas from control and diabetic rats did not result in an increase of TCA cycle flux, suggesting that mitochondrial hyperpolarization is not the source of excess ROS in DR (89). Collectively, while much of the data regarding mitochondrial contribution to ROS production in response to hyperglycemia is compelling, this hypothesis still requires a mechanistic explanation to describe why elevated ATP and NADH fail to prevent excess TCA cycle flux and normal, negative feedback regulation. In addition, it is not yet clear how mitochondrial ROS production regulates such disparate functions as the hexosamine biosynthetic pathway or the polyol pathway in the cytoplasm.

\section{$N A D(P) H$ Oxidase}

$\mathrm{NAD}(\mathrm{P}) \mathrm{H}$ oxidases are membrane-associated enzymes that catalyze the 1-electron reduction of oxygen using $\mathrm{NADH}$ or NADPH as the electron donor (Fig. 5). NADPH oxidase in phagocytic cells is a multiprotein complex consisting of membrane-bound NOX2 and p22phox, cytoplasmic p47phox and p67phox, and the GTPase Rac. In addition to these subunits, vascular endothelial cells also express the NOX2 homologues NOX1, NOX4, and NOX5 (44). NADPH oxidase can be activated by $\mathrm{G}$ protein-coupled receptor agonists, cytokines, growth factors, hypoxia-reoxygenation, and mechanical stimulation (74). Phosphorylation of p47phox is a key post-translational modification involved in the activation of NADPH oxidase and PKC isoforms are believed to be the major kinases responsible for this event (44). This is of particular relevance since the activation of PKC isoforms has been implicated as a key factor in the pathogenesis of diabetes (18).

Increased activity of $\mathrm{NAD}(\mathrm{P}) \mathrm{H}$ oxidase has been observed in diabetic patients and animals. In a model of non-insulindependent diabetes (BBZ/Wor rat), higher activity of NADH oxidase-dependent $\mathrm{H}_{2} \mathrm{O}_{2}$ production was visualized using electron microscopy of the retinal blood vessels of diabetic rats. In addition, this increase in $\mathrm{H}_{2} \mathrm{O}_{2}$ was positively correlated with increased vascular endothelial growth factor (VEGF) expression $(40,41)$. The activity of NAD(P)H oxidase and expression of enzymatic subunits was increased in the aorta of diabetic rats (64) and in both the saphenous vein and internal mammary artery of diabetic patients (53). Apocynin, an inhibitor of NADPH oxidase, blocked the increased retinal leukostasis observed in the streptozotocin (STZ)-induced diabetic rat model (22). Deletion of NOX2 or treatment with apocynin in a mouse model prevented the diabetes-induced increase in ROS formation, intercellular adhesion molecule 
(ICAM)-1 expression, leukostasis, and vascular permeability (5). AGE-induced permeability in rat retinas was inhibited by apocynin, indicating a role for NADPH oxidase downstream of RAGE activation (105). Aortic endothelial cells in culture exposed to high glucose increased free radical production as measured by electron spin resonance (ESR), an effect that was abolished when inhibitors of NAD $(\mathrm{P}) \mathrm{H}$ oxidase and PKC were used (57). These cell culture studies were further supported by in vivo experiments using STZ-induced diabetic rats. Using ESR, an increase in oxidative stress was observed in the abdominal area of diabetic rats in vivo and this effect was normalized by treatment with either a PKC-specific inhibitor or an NAD(P)H oxidase inhibitor (97). Taken together, these studies suggest a key role for PKCdependent activation of $\mathrm{NAD}(\mathrm{P}) \mathrm{H}$ oxidase in the production of ROS in diabetes.

Statins have also been shown to modulate NADPH oxidase in DR. Statins are a class of drugs widely prescribed to treat hyperlipidemia, and in addition to their ability to reduce the cardiovascular complications of diabetes, statins have also been shown to improve signs of DR (110). Simvastatin was shown to decrease the expression of both NOX2 and p47 phox, signal transducer and activator of transcription 3 (STAT3) activation, the formation of ROS, VEGF expression, and vascular leakage in the retinas of STZ-induced diabetic rats (4). A recent study by Li et al. showed that both NOX4 and VEGF expression were increased in the retinas of $\mathrm{db} / \mathrm{db}$ mice, an effect that was abrogated by lovastatin. Moreover, siRNAmediated depletion of NOX4 in $\mathrm{db} / \mathrm{db}$ mice significantly decreased NADPH oxidase activity, VEGF expression, and retinal vascular permeability. These results were confirmed in hypoxia and high glucose-treated retinal capillary endothelial cells and are consistent with the hypothesis that lovastatin inhibits NOX4, resulting in decreased VEGF expression and reduced vascular permeability in diabetic animals (73). These studies provide evidence that statins, either directly or indirectly, have the ability to affect the function of NADPH oxidase and lower the formation of ROS in the diabetic retina. Statins inhibit 3-hydroxy-3-methyl-glutaryl coenzyme A reductase, one of the rate-limiting steps in cholesterol biosynthesis. In addition to blocking the production of cholesterol in cells, statins also inhibit isoprenoid biosynthesis, which is thought to account for many of the anti-inflammatory effects of these drugs (116). Therefore, more mechanistic studies are required to determine the direct role of statins in BRB regulation.

\section{Xanthine oxidase}

The two terminal reactions of purine degradation are catalyzed by the enzyme xanthine oxidoreductase (XOR) that, in the form of xanthine oxidase $(\mathrm{XO})$, produces ROS. $\mathrm{XO}$ catalyzes the conversion of hypoxanthine to xanthine and xanthine to uric acid reducing oxygen and generating ROS in each step (55) and the expression of XO has been detected in capillary endothelium (58). Inhibition of xanthine oxidase with allopurinol improved nonretinal vascular and neural function in an STZ rat model of diabetes (56). Moreover, cytokines and hypoxia regulate $X O R$ gene expression in a variety of cell and organ systems (16), indicating a potential role for this enzyme in DR pathogenesis. However, current evidence for a direct role of $\mathrm{XO}$ in DR is lacking.

\section{Nrf2/ARE}

In addition to production of ROS, the synthesis of ROS scavengers and antioxidant enzymes contributes to the redox state of the cell. A number of transcriptional factors are responsive to cellular redox state and in particular, NF-E2related factor-2 (Nrf2) acts through the antioxidant response element (ARE) inducing the expression of antioxidant genes in vascular cells (45). These genes include glutathione reductase, $\mathrm{NAD}(\mathrm{P}) \mathrm{H}$ :quinone reductase, and glutathione S-transferase among others (99). Evidence from Nrf2 knockout mice indicate that this transcription factor contributes to the cellular control of ROS production since deletion of Nrf2 enhanced ROS production and amplified the pathology of diabetic nephropathy compared to wild-type mice $(59,111)$. However, evidence for a direct role of Nrf2 in DR is lacking and is an area for future research.

\section{Growth Factors and Cytokines in Diabetic Retinopathy}

The diabetic condition promotes a retinal inflammatory response as observed by nuclear factor- $\kappa \mathrm{B}(\mathrm{NF}-\kappa \mathrm{B})$ activation (19) and induction of pro-inflammatory molecules such as ICAM-1. Increased ICAM-1 and other cell adhesion molecules promote leukostasis, resulting in increased vascular permeability and further exacerbating the inflammatory milieu of the retina $(14,79)$. However, no evidence of frank leukocyte infiltration has been observed in the retina. Leukostasis is also thought to contribute to breakdown of the BBB under pathological conditions (23a); however, the exact cell type that adheres to the retinal vasculature in diabetes remains to be elucidated. Thus, the pathology in DR may result from hyperglycemia-induced oxidative stress in endothelial cells, as discussed above or may occur indirectly, in which the diabetic condition induces production of cytokines from a number of potential cell types that act on the vascular endothelium and alter the BRB. A study by Busik et al. (19) in 2008 examined the role of high glucose and cytokines in the generation of ROS and the activation of inflammatory and apoptotic pathways in HREC. Significantly, this study found that treating HREC with high glucose did not increase glucose consumption nor increase the production of ROS, activate NF- $\kappa \mathrm{B}$ or mitogen-activated protein kinase (MAPK) pathways, induce tyrosine phosphorylation, nor increase interleukin (IL)- $1 \beta$, or tumor necrosis factor (TNF)- $\alpha$ production. In contrast, high glucose treatment resulted in increased glucose consumption and IL- $1 \beta$ production in human RPE and Müller cells. Moreover, cytokine treatment of HREC resulted in increased glucose consumption, ROS production, MAPK phosphorylation, NF- $\kappa$ B activation, tyrosine phosphorylation, and caspase activation (19). This study points to an important role for the production of cytokines by nonendothelial retinal cells in the vascular pathogenesis of DR.

Also in support of an indirect effect of hyperglycemia on the endothelial cell tight junction complex, high glucose failed to increase endothelial permeability to $70 \mathrm{kDa}$ rhodamine-Bisothiocyanate (RITC) dextran, 467 Da tetramethylrhodamine, or the transport of water, and failed to alter ZO-1 immunolocalization or claudin-5 expression in BREC (74a). However, high glucose treatment induced Müller cell translational regulation of VEGF both in cell culture and in the retina without affecting VEGF mRNA content and gene 
deletion of eukaryotic initiating factor $4 \mathrm{E}$ binding proteins 1 and 2 blocked the high glucose induction of VEGF protein translation (95).

\section{VEGF}

VEGF promotes both vascular permeability and angiogenesis and is elevated in ocular tissues from patients with PDR $(2,3,75,76)$. Recent clinical trials demonstrating the effectiveness of anti-VEGF antibody therapy in promoting visual acuity in conjunction with laser treatment attests to the importance of this cytokine in DR (42). Direct measures of water and solute transport across BREC monolayers demonstrate that VEGF induces permeability to both fluids and solutes $(21,27,71)$.

Mechanisms of VEGF-induced vascular permeability are beginning to be elucidated. In particular, occludin regulation by VEGF signal transduction is emerging as an essential component of tight junction regulation in the retina. Mice that do not express occludin form tight junctions with normal morphological appearance and barrier function in intestinal epithelia. However, these mice have abnormalities in several tissues, including calcification in the brain that suggests a complex role for occludin in tight junction regulation (92). STZ-induced diabetes in rats has been shown to increase vascular permeability, reduce occludin content in the retina (8), and alter its distribution from continuous cell border localization to intracellular punctae (11). Subsequently, this redistribution of occludin in diabetes was linked to increased vascular permeability (12). Concanavalin A (ConA) is a plant lectin with a specific binding affinity for $\alpha$-D-glucosyl and $\alpha$-D-mannosyl glycoproteins, and will therefore bind to endothelial basement membranes. ConA binding in STZ-diabetic rat retinas was associated with redistribution of occludin staining from the plasma membrane to the cell interior in retinal vascular endothelial cells (Fig. 6), an effect that was also observed after intraocular injection of VEGF. VEGF was also shown to increase occludin phosphorylation in rat retinal vasculature and endothelial cell culture (7). PKC activation by VEGF was later found to be necessary and sufficient for occludin phosphorylation (54). Specifically, the classic $\beta$ isoform of PKC mediates VEGFinduced phosphorylation of occludin since a PKC $\beta$-specific inhibitor as well as expression of a dominant negative PKC $\beta$ mutant abolished VEGF induced occludin phosphorylation and inhibited endothelial permeability (54). Recently, mass spectrometry was used to identify five phosphorylation sites on occludin following VEGF treatment (98). Phosphorylation at serine 490 was subsequently shown to be essential for VEGF-induced ubiquitination, internalization of occludin, and increased endothelial permeability in response to VEGF (Fig. 7) (83). This work provides a mechanistic description of how VEGF, a growth factor known to play a role in DR pathogenesis, stimulates signal transduction in endothelial cells resulting in tight junction alterations and increased permeability.

\section{Inflammatory cytokines}

In addition to growth factors, inflammatory cytokines such as IL- $1 \beta$ and TNF- $\alpha$ are increased in DR and may contribute to vascular defects. IL- $1 \beta$ is elevated in the retina of diabetic

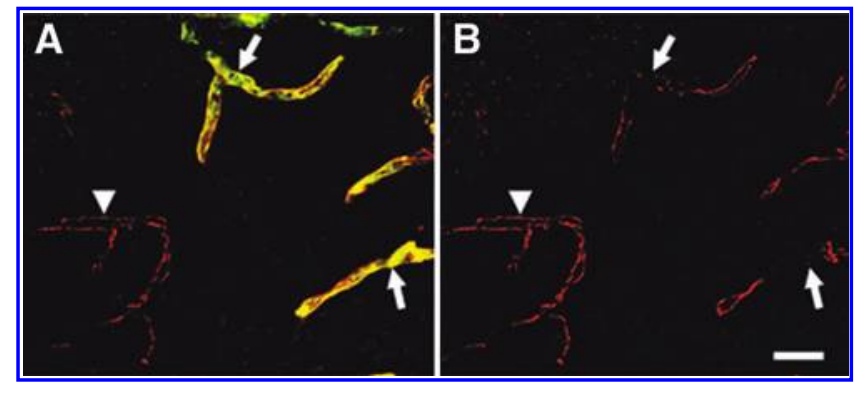

FIG. 6. Increased vascular permeability corresponds to regions of reduced occludin immunoreactivity. Concanavalin $\mathrm{A}$ (ConA) is a plant lectin with binding affinity for $\alpha$-D-glucosyl and $\alpha$-D-mannosyl glycoproteins and will therefore bind to the endothelial basement membrane. Rats were perfused with ConA after 1 month of STZ diabetes, and the retinas were labeled with a polyclonal antibody to occludin. Whole-mounted retinas were viewed by confocal microscopy. Single confocal images from the outer plexiform layer capillary bed are shown. (A) A compound image of ConA (green) and occludin (red); (B) the same field photographed with the laser for ConA excitation turned off to show occludin immunoreactivity alone. Many capillaries were labeled with ConA (A, arrows) but some were not (A, arrowhead). The vessels with ConA binding had less occludin (B, arrows), whereas those that had less ConA binding had more occludin immunoreactivity (B, arrowhead). These data suggest that paracellular permeability was increased in regions with cellular redistribution of occludin. Magnification, X60. Bar, $20 \mu \mathrm{m}$. This figure is re-published with permission from (12). (To see this illustration in color the reader is referred to the web version of this article at www.liebertonline.com/ars).

animals $(48,69)$. Caspase- 1 protease cleaves the precursor form of IL- $1 \beta$, forming the mature peptide (49) and is activated in the retinas of diabetic mice, humans, and high glucose-treated retinal Müller cells (80, 81, 104). Minocycline, a tetracycline derivative that inhibits caspase- 1 as well as a multitude of additional targets, blocked caspase- 1 activity and IL- $1 \beta$ production in the retina of mice at 2 months of diabetes and prevented retinal capillary degradation at 6 months of diabetes. Diabetic mice deficient in the IL-1 receptor demonstrate decreased caspase activation and reduced formation of acellular capillaries as compared to diabetic wild-type mice, indicating a role for IL- $1 \beta$ in DR pathogenesis in this animal model (104).

Expression of both TNF- $\alpha$ and IL- $1 \beta$ were elevated in the vitreous and serum of patients with PDR (28) and TNF- $\alpha$ serves as an independent serum marker for PDR in type I diabetic patients (52). TNF- $\alpha$ expression was elevated in NPDR as well (94). Further support for a role of inflammation in DR comes from mice with gene deletions in either ICAM-1 or its binding partner CD18. Studies examining retinal pathology in diabetic mice with either of these gene deletions indicate that these proteins are required for the increased leukocyte adhesion to the retinal vasculature and increased permeability, acellular capillaries, and pericyte ghosts observed in the diabetic retina (60). Increased leukocyte adhesion, vascular leakage, and ICAM-1 expression, but not VEGF expression, were reduced by a soluble TNF- $\alpha$ receptor $/ F_{c}$ construct (etanercept) in diabetic rat retinas indicating a key role for TNF- $\alpha$ in vascular leakage independent of VEGF (61). In addition, increased TNF$\alpha$ levels were observed and treatment with pegsunercept, a 


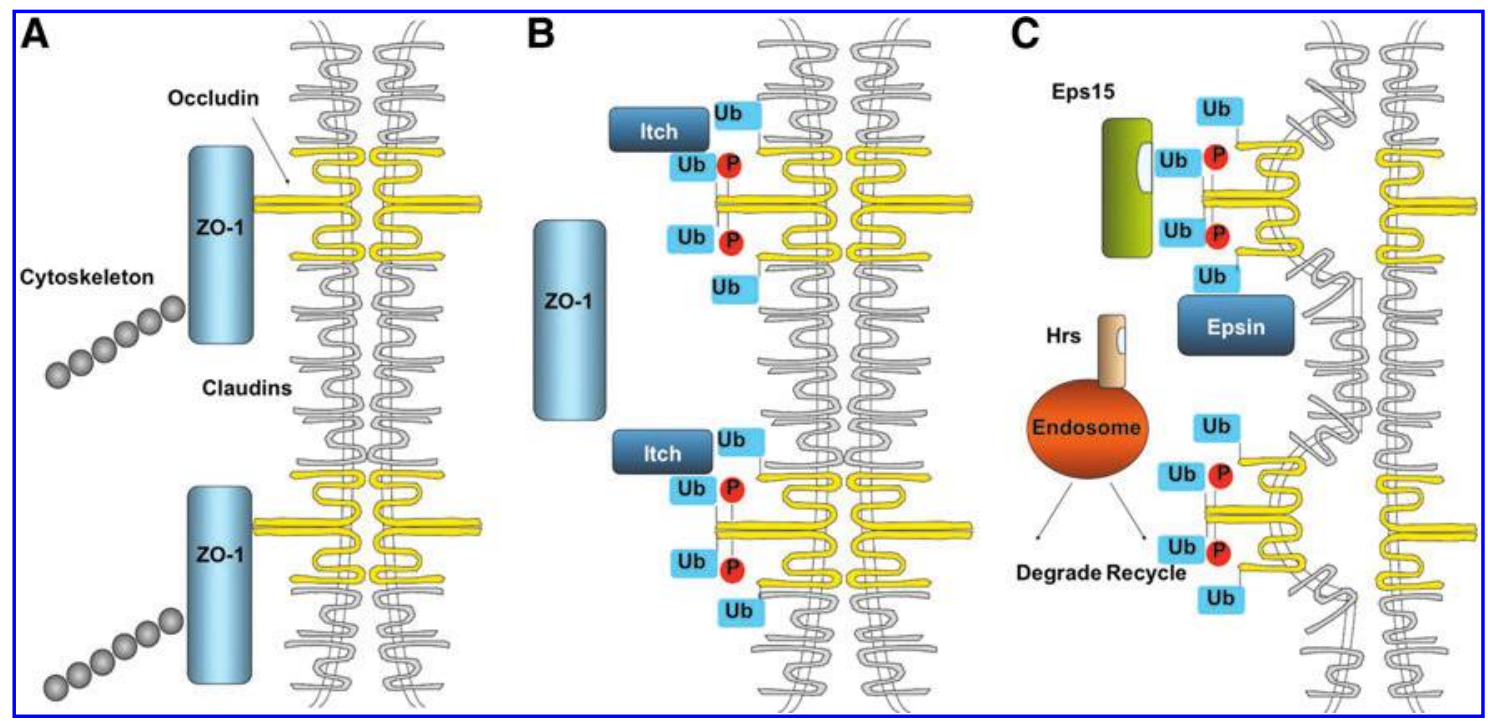

FIG. 7. VEGF induces occludin phosphorylation and ubiquitination. Tight junction localization and interaction of occludin with ZO-1 in the absence of VEGF (A). VEGF induces serine 490 phosphorylation of occludin by PKC $\beta$, followed by ubiquitination (B). Occludin subsequently interacts with Epsin-1, epidermal growth factor receptor pathway substrate 15 (Eps15), and hepatocyte growth factor-regulated tyrosine kinase substrate (Hrs). These proteins are modulators of intracellular trafficking that contain the ubiquitin-interacting motif. These events lead to internalization of occludin and other tight junction proteins and increased vascular permeability $(\mathbf{C})$. (To see this illustration in color the reader is referred to the web version of this article at www.liebertonline.com/ars).

second-generation TNF- $\alpha$ inhibitor, blocked the increased endothelial and pericyte apoptosis, and pericyte ghost and acellular capillary formation in rat models of both type 1 and 2 diabetes (15). An examination of TNF- $\alpha$ induced permeability reveals a mechanism with several unique features compared to VEGF induced permeability. TNF- $\alpha$ does not induce occludin Ser490 phosphorylation and increases occludin mRNA and protein expression. Conversely, TNF- $\alpha$ reduces claudin 5 and ZO-1 mRNA and protein expression in an NF-kB dependent manner and induces a profound disorganization of the tight junction complex (10). Similar to retinal endothelial cells, TNF- $\alpha$ also causes barrier loss in cultured intestinal epithelial monolayers and the TNF-neutralizing antibody infliximab restores the intestinal barrier in Crohn's disease patients (59a, 96). Collectively, these data demonstrate a contribution of inflammatory cytokines to the pathogenesis of DR including loss of BRB function.

\section{The Interaction of Reactive Oxygen Species and Cytokines in DR}

ROS appear to contribute to vascular permeability in DR, but a clear mechanism has not yet emerged. Since ROS are known to modulate signal transduction, it is possible that ROS production results in tight junction alterations through the induction of growth factors and cytokines. For example, studies have demonstrated that ROS derived from NADPH oxidase activate kinases such as Akt, Src, and MAPKs as well as the transcription factors NF- $\kappa \mathrm{B}$, activator protein-1, p53, Etwenty six, and hypoxia-inducible factor-1 (44). A number of studies support a role for ROS in the activation of signal transduction pathways that result in increased production of growth factors and cytokines.

The formation of RNOS has been reported to stimulate growth factor expression in DR. Nitric oxide (NO) rapidly reacts with superoxide to form peroxynitrite, which can lead to lipid peroxidation, oxidation of sulfhydryl groups, DNA damage, and disturbed electron transport. The reaction of peroxynitrite with proteins may result in the formation of nitrotyrosine residues that can be used as a marker for peroxynitrite production (77). Inhibition of NOS has been shown to prevent DR pathology in rats $(32,38,66)$. Inhibition of NOS or scavenging of peroxynitrite prevented the increased permeability, formation of lipid peroxides, nitrotyrosine, and increased expression of VEGF observed in the retinas of diabetic rats (38). In vitro, high glucose treatment of retinal endothelial cells resulted in increased production of endothelial NOS (eNOS) protein, NOS activity, $\mathrm{NO}$, superoxide, and nitrotyrosine formation. Increased superoxide and peroxynitrite production was shown to be the result of high glucose-induced uncoupling of eNOS leading to the production of superoxide instead of $\mathrm{NO}$ and L-citrulline. This uncoupling may occur when the NOS substrate, L-arginine, or its cofactor, tetrahydrobiopterin (BH4), is limited (36). In microvascular endothelial cells, peroxynitrite induced increased expression of VEGF mRNA and protein, an effect that was mediated by the transcription factor STAT3 (90). However, this area remains controversial since other studies have failed to detect hyperglycemia-induced changes to endothelial cell function $(19,74 a)$.

In addition to VEGF expression, peroxynitrite also mediates VEGF signal transduction. High glucose treatment of retinal endothelial cells has been shown to result in apoptosis through the tyrosine nitration of PI 3-kinase by peroxynitrite, resulting in reduced activity of Akt-1 kinase and resultant pro-survival signaling (39). In addition, the peroxynitrite decomposition catalyst 5,10,15,20-tetrakis(4-sulfonatophenyl)prophyrinato iron (III) (FeTPPS) inhibited the sustained phosphorylation of vascular endothelial growth factor re- 
FIG. 8. Possible mechanisms of tight junction dysregulation by hyperglycemia. In the non-disease state, cells of the neural retina, including glial cells and pericytes, produce pro-barrier factors that contribute to the maintenance of tight junction integrity and the BRB (A). Hyperglycemia can disrupt tight junction integrity by either a direct or indirect interaction with endothelial cells. Hyperglycemia may directly lead to mitochondrial, NADPH oxidase, and sorbitol pathway production of oxidative stress, ROS and RNOS in endothelial cells leading to tight junction disruption and apo-
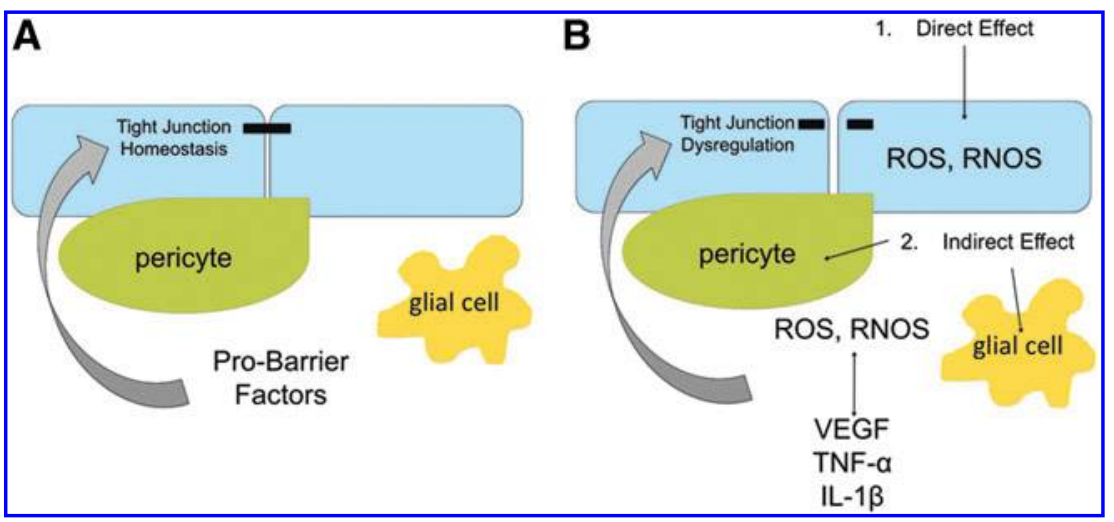
ptosis (B). Alternatively, hyperglycemia may result in the production of cytokines and growth factors by cells of the neural retina which then interact with endothelial cells thereby altering tight junction integrity and increasing vascular permeability (B). It is likely that cytokines and ROS interact with each other to result in the complete pathology of DR. (To see this illustration in color the reader is referred to the web version of this article at www.liebertonline.com/ars).

ceptor (VEGFR)2 induced by VEGF, and subsequent endothelial cell migration and tube formation. These data suggest a role for VEGF-induced peroxynitrite formation in the VEGF signal transduction pathway (37).

There is also evidence for an interaction of ROS and IL-1 $\beta$. Intraocular injection of IL- $1 \beta$ in normal rats increased oxidative stress as measured by DNA oxidation and NO production. Conversely, the increased levels of IL- $1 \beta$ in the diabetic rat retina were normalized in a prevention trial with antioxidant treatment over a 2 -month period (69). In addition, BREC treated with high glucose had increased expression of IL-1 $\beta$ and BREC treated with IL- $1 \beta$ had increased NO expression, caspase- 3 activity, and apoptosis (70), suggesting a role for IL- $1 \beta$ in endothelial cell death.

Finally, pigment epithelium-derived factor (PEDF) is a potent inhibitor of angiogenesis and anti-permeability factor originally identified in retinal pigment epithelial (RPE) cells $(102,26)$. Decreased levels of PEDF have been observed in the vitreous and aqueous humor from patients with PDR $(17,34$, 87, 88). The decreased levels of PEDF and increased levels VEGF, NADPH oxidase activity, oxidative damage, and vascular leakage observed in the retinas of diabetic rats were prevented by systemic treatment with PEDF (112). In BREC, PEDF blocks the increased expression of VEGF mRNA and protein induced by high glucose through increased expression of UCP-2 and the subsequent decrease in mitochondrial ROS production and Janus kinase 2/STAT3 activation (112). These studies indicate that PEDF acts to prevent generation of ROS and inflammatory mediators in the diabetic retina thereby reducing vascular leakage.

\section{Conclusion}

In conclusion, the vascular pathology of DR is likely the result of a complex interaction of growth factors, cytokines, and ROS induced by the action of diabetes-associated metabolic abnormalities. Understanding which cells are primarily affected by these metabolic abnormalities and providing a mechanistic understanding of the resultant pathology will yield novel insight for therapeutic development. One potential model that is emerging suggests that metabolic abnormalities, including hyperglycemia, contribute to oxidative stress and subsequent ROS production in support cells such as glia, microglia, and pericytes. These cells respond with increased cytokine (TNF- $\alpha$, IL- $-1 \beta)$, and growth factor (VEGF) production, potentially as a compensation for the metabolic distress but eventually leading to maladaptation and subsequent alterations to the tight junctions increasing the BRB permeability and preventing normal neuronal function. Production of ICAM-1 and leukostasis leads to vascular occlusion and creates regions of hypoxia, further exacerbating the retinal pathology. Ultimately, continued ROS production and inflammation leads to loss of pericytes and vascular endothelial cells, and this vascular degeneration may contribute to loss of visual function (Fig. 8). The relative contribution of each of the diabetesinduced alterations to disease pathology and loss of vision remains to be determined. However, the potential effectiveness of anti-VEGF treatment and anti-inflammatory steroids provide hope that effective, long-term medical intervention to preserve vision is possible.

\section{References}

1. A randomized trial of sorbinil, an aldose reductase inhibitor, in diabetic retinopathy. Sorbinil Retinopathy Trial Research Group. Arch Ophthalmol 108: 1234-1244, 1990.

2. Adamis AP, Miller JW, Bernal MT, D'Amico DJ, Folkman J, Yeo TK, and Yeo KT. Increased vascular endothelial growth factor levels in the vitreous of eyes with proliferative diabetic retinopathy. Am J Ophthalmol 118: 445-450, 1994.

3. Aiello LP, Avery RL, Arrigg PG, Keyt BA, Jampei HD, Shah ST, Pasquale LR, Thieme H, Iwamoto MA, Park JE, Nguyen HV, Aiello LM, Ferrara N, and King GL. Vascular endothelial growth factor in ocular fluid of patients with diabetic retinopathy and other retinal disorders. $N$ Engl J Med 331: 1480-1487, 1994.

4. Al-Shabrawey M, Bartoli M, El-Remessy AB, Ma G, Matragoon S, Lemtalsi T, Caldwell RW, and Caldwell RB. Role of NADPH oxidase and Stat3 in statin-mediated protection against diabetic retinopathy. Invest Ophthalmol Vis Sci 49: 3231-3238, 2008.

5. Al-Shabrawey M, Rojas M, Sanders T, Behzadian A, ElRemessy A, Bartoli M, Parpia AK, Liou G, and Caldwell RB. Role of NADPH oxidase in retinal vascular inflammation. Invest Ophthalmol Vis Sci 49: 3239-3244, 2008. 
6. Antonetti DA, Barber AJ, Bronson SK, Freeman WM, Gardner TW, Jefferson LS, Kester M, Kimball SR, Krady JK, LaNoue KF, Norbury CC, Quinn PG, Sandirasegarane L, and Simpson IA. Diabetic retinopathy: Seeing beyond glucose-induced microvascular disease. Diabetes 55: 24012411, 2006.

7. Antonetti DA, Barber AJ, Hollinger LA, Wolpert EB, and Gardner TW. Vascular endothelial growth factor induces rapid phosphorylation of tight junction proteins occludin and zonula occluden 1 . A potential mechanism for vascular permeability in diabetic retinopathy and tumors. L Biol Chem 274: 23463-23467, 1999.

8. Antonetti DA, Barber AJ, Khin S, Lieth E, Tarbell JM, and Gardner TW. Vascular permeability in experimental diabetes is associated with reduced endothelial occludin content: Vascular endothelial growth factor decreases occludin in retinal endothelial cells. Penn State Retina Research Group. Diabetes 47: 1953-1959, 1998.

9. Asnaghi V, Gerhardinger C, Hoehn T, Adeboje A, and Lorenzi M. A role for the polyol pathway in the early neuroretinal apoptosis and glial changes induced by diabetes in the rat. Diabetes 52: 506-511, 2003.

10. Aveleira CA, Lin CM, Abcouwer SF, Ambrosio AF, and Antonetti DA. TNF- $\alpha$ signals through $\mathrm{PKC} \zeta / \mathrm{NF}-\kappa \mathrm{B}$ to alter the tight junction complex and increase retinal endothelial cell permeability. Diabetes 59: 2872-2882, 2010.

11. Barber AJ, Antonetti DA, and Gardner TW. Altered expression of retinal occludin and glial fibrillary acidic protein in experimental diabetes. The Penn State Retina Research Group. Invest Ophthalmol Vis Sci 41: 3561-3568, 2000.

12. Barber AJ and Antonetti DA. Mapping the blood vessels with paracellular permeability in the retinas of diabetic rats. Invest Ophthalmol Vis Sci 44: 5410-5416, 2003.

13. Barnett PA, Gonzalez RG, Chylack LT, Jr., and Cheng HM. The effect of oxidation on sorbitol pathway kinetics. Diabetes 35: 426-432, 1986.

14. Barouch FC, Miyamoto K, Allport JR, Fujita K, Bursell SE, Aiello LP, Luscinskas FW, and Adamis AP. Integrinmediated neutrophil adhesion and retinal leukostasis in diabetes. Invest Ophthalmol Vis Sci 41: 1153-1158, 2000.

14a. Bazzoni G. Pathobiology of junctional adhesion molecules. Antioxid Redox Signal 15: 1221-1234, 2011.

15. Behl Y, Krothapalli P, Desta T, DiPiazza A, Roy S, and Graves DT. Diabetes-enhanced tumor necrosis factor-alpha production promotes apoptosis and the loss of retinal microvascular cells in type 1 and type 2 models of diabetic retinopathy. Am J Pathol 172: 1411-1418, 2008.

16. Berry CE and Hare JM. Xanthine oxidoreductase and cardiovascular disease: molecular mechanisms and pathophysiological implications. J Physiol 555(Pt 3):589-606, 2004.

16a. Blasig IE, Bellmann C, Cording J, del Vecchio G, Zwanziger D, Huber $\mathrm{O}$, and Haseloff RF. Occludin protein family: oxidative stress and reducing conditions. Antioxid Redox Signal 15: 1195-1219, 2011.

17. Boehm BO, Lang G, Volpert O, Jehle PM, Kurkhaus A, Rosinger S, Lang GK, and Bouck N. Low content of the natural ocular anti-angiogenic agent pigment epithelium-derived factor (PEDF) in aqueous humor predicts progression of diabetic retinopathy. Diabetologia 46: 394-400, 2003.

18. Brownlee M. Biochemistry and molecular cell biology of diabetic complications. Nature 414: 813-820, 2001.

19. Busik JV, Mohr S and Grant MB. Hyperglycemia-induced reactive oxygen species toxicity to endothelial cells is dependent on paracrine mediators. Diabetes 57: 1952-1965, 2008.
20. Chakrabarti S and Sima AA. Effect of aldose reductase inhibition and insulin treatment on retinal capillary basement membrane thickening in BB rats. Diabetes 38: 1181-1186, 1989.

21. Chang YS, Munn LL, Hillsley MV, Dull RO, Yuan J, Lakshminarayanan S, Gardner TW, Jain RK, and Tarbell JM. Effect of vascular endothelial growth factor on cultured endothelial cell monolayer transport properties. Microvasc Res 59: 265-277, 2000.

22. Chen P, Guo AM, Edwards PA, Trick G, and Scicli AG. Role of NADPH oxidase and ANG II in diabetes-induced retinal leukostasis. Am I Physiol Regul Integr Comp Physiol 293: R1619-1629, 2007.

23. Cheung AK, Fung MK, Lo AC, Lam TT, So KF, Chung SS, and Chung SK. Aldose reductase deficiency prevents diabetes-induced blood-retinal barrier breakdown, apoptosis, and glial reactivation in the retina of $\mathrm{db} / \mathrm{db}$ mice. Diabetes 54: 3119-3125, 2005.

23a. Coisne $C$ and Engelhardt B. Tight junctions in brain barriers during CNS inflammation. Antioxid Redox Signal 15: 1285-1303, 2011.

24. Cui Y, Xu X, Bi H, Zhu Q, Wu J, Xia X, Qiushi R, and Ho PC. Expression modification of uncoupling proteins and MnSOD in retinal endothelial cells and pericytes induced by high glucose: the role of reactive oxygen species in diabetic retinopathy. Exp Eye Res 83: 807-816, 2006.

25. Dagher Z, Park YS, Asnaghi V, Hoehn T, Gerhardinger C, and Lorenzi M. Studies of rat and human retinas predict a role for the polyol pathway in human diabetic retinopathy. Diabetes 53: 2404-2411, 2004.

26. Dawson DW, Volpert OV, Gillis P, Crawford SE, Xu H, Benedict W, and Bouck NP. Pigment epithelium-derived factor: A potent inhibitor of angiogenesis. Science 285: 245248, 1999.

27. DeMaio L, Antonetti DA, Scaduto RC, Jr., Gardner TW, and Tarbell JM. VEGF increases paracellular transport without altering the solvent-drag reflection coefficient. Microvasc Res 68: 295-302, 2004.

28. Demircan N, Safran BG, Soylu M, Ozcan AA, and Sizmaz S. Determination of vitreous interleukin-1 (IL-1) and tumour necrosis factor (TNF) levels in proliferative diabetic retinopathy. Eye (Lond) 20: 1366-1369, 2006.

29. Diederen RM, Starnes CA, Berkowitz BA, and Winkler BS. Reexamining the hyperglycemic pseudohypoxia hypothesis of diabetic oculopathy. Invest Ophthalmol Vis Sci 47: 2726-2731, 2006.

30. Du XL, Edelstein D, Dimmeler S, Ju Q, Sui C, and Brownlee M. Hyperglycemia inhibits endothelial nitric oxide synthase activity by posttranslational modification at the Akt site. L Clin Invest 108: 1341-1348, 2001.

31. Du XL, Edelstein D, Rossetti L, Fantus IG, Goldberg H, Ziyadeh F, Wu J, and Brownlee M. Hyperglycemia-induced mitochondrial superoxide overproduction activates the hexosamine pathway and induces plasminogen activator inhibitor-1 expression by increasing Sp1 glycosylation. $\underline{\text { Proc }}$ Natl Acad Sci USA 97: 12222-12226, 2000.

32. Du Y, Smith MA, Miller CM, and Kern TS. Diabetesinduced nitrative stress in the retina, and correction by aminoguanidine. LNeurochem 80: 771-779, 2002.

33. Duh EJ. (Ed). Diabetic Retinopathy. Totowa, NJ: Humana Press, 2008.

34. Duh EJ, Yang HS, Haller JA, De Juan E, Humayun MS, Gehlbach P, Melia M, Pieramici D, Harlan JB, Campochiaro PA, and Zack DJ. Vitreous levels of pigment epitheliumderived factor and vascular endothelial growth factor: Im- 
plications for ocular angiogenesis. Am J Ophthalmol 137: 668-674, 2004.

35. Dvornik E, Simard-Duquesne N, Krami M, Sestanj K, Gabbay KH, Kinoshita JH, Varma SD, and Merola LO. Polyol accumulation in galactosemic and diabetic rats: Control by an aldose reductase inhibitor. Science 182: 11461148, 1973.

36. El-Remessy AB, Abou-Mohamed G, Caldwell RW, and Caldwell RB. High glucose-induced tyrosine nitration in endothelial cells: Role of eNOS uncoupling and aldose reductase activation. Invest Ophthalmol Vis Sci 44: 3135-3143, 2003.

37. El-Remessy AB, Al-Shabrawey $\mathrm{M}$, Platt DH, Bartoli $\mathrm{M}$, Behzadian MA, Ghaly N, Tsai N, Motamed K, and Caldwell RB. Peroxynitrite mediates VEGF's angiogenic signal and function via a nitration-independent mechanism in endothelial cells. FASEB I 21: 2528-2539, 2007.

38. El-Remessy AB, Behzadian MA, Abou-Mohamed G, Franklin T, Caldwell RW, and Caldwell RB. Experimental diabetes causes breakdown of the blood-retina barrier by a mechanism involving tyrosine nitration and increases in expression of vascular endothelial growth factor and urokinase plasminogen activator receptor. Am J Pathol 162: 1995-2004, 2003.

39. El-Remessy AB, Bartoli M, Platt DH, Fulton D, and Caldwell RB. Oxidative stress inactivates VEGF survival signaling in retinal endothelial cells via PI 3-kinase tyrosine nitration. I Cell Sci 118: 243-252, 2005.

40. Ellis EA, Grant MB, Murray FT, Wachowski MB, Guberski DL, Kubilis PS, and Lutty GA. Increased NADH oxidase activity in the retina of the BBZ/Wor diabetic rat. Free Radic Biol Med 24: 111-120, 1998.

41. Ellis EA, Guberski DL, Somogyi-Mann M, and Grant MB. Increased $\mathrm{H} 2 \mathrm{O} 2$, vascular endothelial growth factor and receptors in the retina of the BBZ/Wor diabetic rat. Free Radic Biol Med 28: 91-101, 2000.

42. Elman MJ, Aiello LP, Beck RW, Bressler NM, Bressler SB, Edwards AR, Ferris FL $3^{\text {rd }}$, Friedman SM, Glassman AR, Miller KM, Scott IU, Stockdale CR, and Sun JK. Randomized trial evaluating ranibizumab plus prompt or deferred laser or triamcinolone plus prompt laser for diabetic macular edema. Ophthalmology 117: 1064-1077, 2010.

43. Erickson KK, Sundstrom JM, and Antonetti DA. Vascular permeability in ocular disease and the role of tight junctions. Angiogenesis 10: 103-117, 2007.

44. Frey RS, Ushio-Fukai M, and Malik AB. NADPH oxidasedependent signaling in endothelial cells: Role in physiology and pathophysiology. Antioxid Redox Signal 11: 791-810, 2009.

45. Gao L and Mann GE. Vascular NAD(P)H oxidase activation in diabetes: A double-edged sword in redox signalling. Cardiovasc Res 82: 9-20, 2009.

46. Gardner TW and Antonetti DA. Novel potential mechanisms for diabetic macular edema: Leveraging new investigational approaches. Curr Diab Rep 8: 263-269, 2008.

47. Gardner TW, Larsen M, Girach A, and Zhi X. Diabetic macular oedema and visual loss: relationship to location, severity and duration. Acta Ophthalmol 87: 709-713, 2009.

48. Gerhardinger C, Costa MB, Coulombe MC, Toth I, Hoehn $\mathrm{T}$, and Grosu P. Expression of acute-phase response proteins in retinal Müller cells in diabetes. Invest Ophthalmol Vis Sci 46: 349-357, 2005.
49. Ghayur T, Banerjee S, Hugunin M, Butler D, Herzog L, Carter A, Quintal L, Sekut L, Talanian R, Paskind M, Wong W, Kamen R, Tracey D, and Allen H. Caspase- 1 processes IFN-gamma-inducing factor and regulates LPS-induced IFN-gamma production. Nature 386: 619-623, 1997.

50. Giardino I, Edelstein D, and Brownlee M. BCL-2 expression or antioxidants prevent hyperglycemia-induced formation of intracellular advanced glycation endproducts in bovine endothelial cells. I Clin Invest 97: 1422-1428, 1996.

51. Gonzalez-Mariscal L, Betanzos A, Nava P, and Jaramillo BE. Tight junction proteins. Prog Biophys Mol Biol 81: 1-44, 2003.

51a. González-Mariscal L, Quirós M, and Díaz-Coránguez M. ZO proteins and redox-dependent processes. Antioxid Redox Signal 15: 1235-1253, 2011.

52. Gustavsson C, Agardh E, Bengtsson B, and Agardh CD. TNF-alpha is an independent serum marker for proliferative retinopathy in type 1 diabetic patients. I Diabetes Complications 22: 309-316, 2008.

53. Guzik TJ, Mussa S, Gastaldi D, Sadowski J, Ratnatunga C, Pillai R, and Channon KM. Mechanisms of increased vascular superoxide production in human diabetes mellitus: Role of $\mathrm{NAD}(\mathrm{P}) \mathrm{H}$ oxidase and endothelial nitric oxide synthase. Circulation 105: 1656-1662, 2002.

54. Harhaj NS, Felinski EA, Wolpert EB, Sundstrom JM, Gardner TW, and Antonetti DA. VEGF activation of protein kinase $C$ stimulates occludin phosphorylation and contributes to endothelial permeability. Invest Ophthalmol Vis Sci 47: 5106-5115, 2006.

55. Hille $R$ and Nishino T. Flavoprotein structure and mechanism. 4. Xanthine oxidase and xanthine dehydrogenase. FASEB J 9: 995-1003, 1995.

56. Inkster ME, Cotter MA, and Cameron NE. Treatment with the xanthine oxidase inhibitor, allopurinol, improves nerve and vascular function in diabetic rats. Eur J Pharmacol 561: 63-71, 2007.

57. Inoguchi $\mathrm{T}$, Li P, Umeda F, Yu HY, Kakimoto M, Imamura M, Aoki T, Etoh T, Hashimoto T, Naruse M, Sano $H$, Utsumi $H$, and Nawata H. High glucose level and free fatty acid stimulate reactive oxygen species production through protein kinase C-dependent activation of NAD(P)H oxidase in cultured vascular cells. Diabetes 49: 1939-1945, 2000.

58. Jarasch ED, Grund C, Bruder G, Heid HW, Keenan TW, and Franke WW. Localization of xanthine oxidase in mammary-gland epithelium and capillary endothelium. Cell 25: 67-82, 1981.

59. Jiang T, Huang Z, Lin Y, Zhang Z, Fang D, and Zhang DD. The protective role of Nrf2 in streptozotocin-induced diabetic nephropathy. Diabetes 59: 850-860, 2010.

59a. John LJ, Fromm M, and Schulzke JD. Epithelial barriers in intestinal inflammation. Antioxid Redox Signal 15: 12551270, 2011.

60. Joussen AM, Poulaki V, Le ML, Koizumi K, Esser C, Janicki H, Schraermeyer U, Kociok N, Fauser S, Kirchhof B, Kern TS, and Adamis AP. A central role for inflammation in the pathogenesis of diabetic retinopathy. FASEB J 18: 14501452, 2004.

61. Joussen AM, Poulaki V, Mitsiades N, Kirchhof B, Koizumi K, Dohmen S, and Adamis AP. Nonsteroidal anti-inflammatory drugs prevent early diabetic retinopathy via TNF-alpha suppression. FASEB I 16: 438-440, 2002.

62. Kanwar M, Chan PS, Kern TS, and Kowluru RA. Oxidative damage in the retinal mitochondria of diabetic mice: 
Possible protection by superoxide dismutase. Invest Ophthalmol Vis Sci 48: 3805-3811, 2007.

63. Kato N, Yashima S, Suzuki T, Nakayama Y, and Jomori T. Long-term treatment with fidarestat suppresses the development of diabetic retinopathy in STZ-induced diabetic rats. I Diabetes Complications 17: 374379, 2003.

64. Kim YK, Lee MS, Son SM, Kim IJ, Lee WS, Rhim BY, Hong $\mathrm{KW}$, and Kim CD. Vascular NADH oxidase is involved in impaired endothelium-dependent vasodilation in OLETF rats, a model of type 2 diabetes. Diabetes 51: 522 527, 2002.

65. Kowluru RA, Atasi L, and Ho YS. Role of mitochondrial superoxide dismutase in the development of diabetic retinopathy. Invest Ophthalmol Vis Sci 47: 1594-1599, 2006.

66. Kowluru RA, Engerman RL, and Kern TS. Abnormalities of retinal metabolism in diabetes or experimental galactosemia VIII. Prevention by aminoguanidine. Curr Eye Res 21: 814-819, 2000.

67. Kowluru RA, Kowluru V, Xiong Y, and Ho YS. Overexpression of mitochondrial superoxide dismutase in mice protects the retina from diabetes-induced oxidative stress. Free Radic Biol Med 41: 1191-1196, 2006.

68. Kowluru RA and Odenbach S. Effect of long-term administration of alpha-lipoic acid on retinal capillary cell death and the development of retinopathy in diabetic rats. Diabetes 53: 3233-3238, 2004.

69. Kowluru RA and Odenbach S. Role of interleukin-1beta in the development of retinopathy in rats: Effect of antioxidants. Invest Ophthalmol Vis Sci 45: 4161-4166, 2004.

70. Kowluru RA and Odenbach S. Role of interleukin-1beta in the pathogenesis of diabetic retinopathy. $\mathrm{Br}$ J Ophthalmol 88: 1343-1347, 2004.

71. Lakshminarayanan S, Antonetti DA, Gardner TW, and Tarbell JM. Effect of VEGF on retinal microvascular endothelial hydraulic conductivity: The role of NO. Invest Ophthalmol Vis Sci 41: 4256-4261, 2000.

72. Lassegue B and Clempus RE. Vascular NAD(P)H oxidases: Specific features, expression, and regulation. $\underline{A m ~ J ~ P h y s i o l ~}$ Regul Integr Comp Physiol 285: R277-297, 2003.

73. Li J, Wang JJ, Yu Q, Chen K, Mahadev K, and Zhang SX. Inhibition of reactive oxygen species by lovastatin downregulates VEGF expression and ameliorates blood-retinal barrier breakdown in $\mathrm{db} / \mathrm{db}$ mice: Role of NADPH oxidase 4. Diabetes 59: 1528-1538, 2010.

74. Li JM and Shah AM. Endothelial cell superoxide generation: Regulation and relevance for cardiovascular pathophysiology. Am I Physiol Regul Integr Comp Physiol 287: R1014-1030, 2004.

74a. Lopez-Quintero SU, Ji XY, Antonetti DA, Tarbell JM. A three-pore model describes transport properties of bovine retinal endothelial cells in normal and elevated glucose. Invest Opthalmol Vis Sci 52: 1171-1180.

75. Lutty GA, McLeod DS, Merges C, Diggs A, and Plouet J. Localization of vascular endothelial growth factor in human retina and choroid. Arch Ophthalmol 114: 971-977, 1996.

76. Malecaze F, Clamens S, Simorre-Pinatel V, Mathis A, Chollet P, Favard C, Bayard F, and Plouet J. Detection of vascular endothelial growth factor messenger RNA and vascular endothelial growth factor-like activity in proliferative diabetic retinopathy. Arch Ophthalmol 112: 1476-1482, 1994.
77. Misko TP, Highkin MK, Veenhuizen AW, Manning PT, Stern MK, Currie MG, and Salvemini D. Characterization of the cytoprotective action of peroxynitrite decomposition catalysts. I Biol Chem 273: 15646-15653, 1998.

78. Miwa K, Nakamura J, Hamada Y, Naruse K, Nakashima E, Kato K, Kasuya Y, Yasuda Y, Kamiya H, and Hotta N. The role of polyol pathway in glucose-induced apoptosis of cultured retinal pericytes. Diabetes Res Clin Pract 60: 1-9, 2003.

79. Miyamoto K, Khosrof S, Bursell SE, Rohan R, Murata T, Clermont AC, Aiello LP, Ogura Y, and Adamis AP. Prevention of leukostasis and vascular leakage in streptozotocin-induced diabetic retinopathy via intercellular adhesion molecule-1 inhibition. Proc Natl Acad Sci USA 96: 10836-10841, 1999.

80. Mohr S. Potential new strategies to prevent the development of diabetic retinopathy. Expert Opin Investig Drugs 13: 189-198, 2004.

81. Mohr S, Xi X, Tang J, and Kern TS. Caspase activation in retinas of diabetic and galactosemic mice and diabetic patients. Diabetes 51: 1172-1179, 2002.

82. Moss SE, Klein R, and Klein BE. The 14-year incidence of visual loss in a diabetic population. Ophthalmology 105: 998-1003, 1998.

83. Murakami T, Felinski EA, and Antonetti DA. Occludin phosphorylation and ubiquitination regulate tight junction trafficking and vascular endothelial growth factor-induced permeability. I Biol Chem 284: 21036-21046, 2009.

84. Nishikawa T, Edelstein D, and Brownlee M. The missing link: A single unifying mechanism for diabetic complications. Kidney Int Suppl 77: S26-30, 2000.

85. Nyengaard JR, Ido Y, Kilo C, and Williamson JR. Interactions between hyperglycemia and hypoxia: implications for diabetic retinopathy. Diabetes 53: 2931-2938, 2004.

86. Obrosova IG, Minchenko AG, Vasupuram R, White L, Abatan OI, Kumagai AK, Frank RN, and Stevens MJ. Aldose reductase inhibitor fidarestat prevents retinal oxidative stress and vascular endothelial growth factor overexpression in streptozotocin-diabetic rats. Diabetes 52 : 864-871, 2003.

87. Ogata N, Nishikawa M, Nishimura T, Mitsuma Y, and Matsumura M. Unbalanced vitreous levels of pigment epithelium-derived factor and vascular endothelial growth factor in diabetic retinopathy. Am J Ophthalmol 134: 348353, 2002.

88. Ogata N, Wang L, Jo N, Tombran-Tink J, Takahashi K, Mrazek D, and Matsumura M. Pigment epithelium derived factor as a neuroprotective agent against ischemic retinal injury. Curr Eye Res 22: 245-252, 2001.

89. Ola MS, Berkich DA, Xu Y, King MT, Gardner TW, Simpson I, and LaNoue KF. Analysis of glucose metabolism in diabetic rat retinas. Am I Physiol Endocrinol Metab 290: E1057-1067, 2006.

89a. Overgaard CE, Daugherty BL, Mitchell LA, and Koval M. Claudins: control of barrier function and regulation in response to oxidant stress. Antioxid Redox Signal 15: 11791193, 2011.

90. Platt DH, Bartoli M, El-Remessy AB, Al-Shabrawey M, Lemtalsi T, Fulton D, and Caldwell RB. Peroxynitrite increases VEGF expression in vascular endothelial cells via STAT3. Free Radic Biol Med 39: 1353-1361, 2005.

91. Saaddine JB, Honeycutt AA, Narayan KM, Zhang X, Klein $\mathrm{R}$, and Boyle JP. Projection of diabetic retinopathy and other major eye diseases among people with diabetes 
mellitus: United States, 2005-2050. Arch Ophthalmol 126: 1740-1747, 2008.

92. Saitou M, Furuse M, Sasaki H, Schulzke JD, Fromm M, Takano H, Noda T, and Tsukita S. Complex phenotype of mice lacking occludin, a component of tight junction strands. Mol Biol Cell 11: 4131-4142, 2000.

93. Sander $\bar{B}$, Larsen $M$, Moldow B, and Lund-Andersen $H$. Diabetic macular edema: passive and active transport of fluorescein through the blood-retina barrier. Invest Ophthalmol Vis Sci 42: 433-438, 2001.

94. Schram MT, Chaturvedi N, Schalkwijk CG, Fuller JH, and Stehouwer CD. Markers of inflammation are cross-sectionally associated with microvascular complications and cardiovascular disease in type 1 diabetes. The EURODIAB Prospective Complications Study. Diabetologia 48: 370-378, 2005.

95. Schrufer TL, Antonetti DA, Sonenberg N, Kimball SR, Gardner TW, and Jefferson LS. Ablation of 4E-BP1/2 prevents hyperglycemia-mediated induction of VEGF expression in the rodent retina and in Muller cells in culture. Diabetes 59: 2107-2116, 2010.

96. Shen L, Su L and Turner JR. Mechanisms and functional implications of intestinal barrier defects. Dig Dis 27: 443449, 2009.

97. Sonta T, Inoguchi T, Tsubouchi H, Sekiguchi N, Kobayashi K, Matsumoto S, Utsumi H, and Nawata H. Evidence for contribution of vascular $\mathrm{NAD}(\mathrm{P}) \mathrm{H}$ oxidase to increased oxidative stress in animal models of diabetes and obesity. Free Radic Biol Med 37: 115-123, 2004.

98. Sundstrom JM, Tash BR, Murakami T, Flanagan JM, Bewley MC, Stanley BA, Gonsar KB, and Antonetti DA. Identification and analysis of occludin phosphosites: A combined mass spectrometry and bioinformatics approach. L Proteome Res 8: 808-817, 2009.

99. Thimmulappa RK, Mai KH, Srisuma S, Kensler TW, Yamamoto $\mathrm{M}$, and Biswal S. Identification of Nrf2-regulated genes induced by the chemopreventive agent sulforaphane by oligonucleotide microarray. Cancer Res 62: 5196-5203, 2002.

100. Thornit DN, Vinten CM, Sander B, Lund-Andersen H, and la Cour M. Blood-retinal barrier glycerol permeability in diabetic macular edema and healthy eyes: Estimations from macular volume changes after peroral glycerol. Invest Ophthalmol Vis Sci 51: 2827-2834, 2009.

101. Tilton RG, Chang K, Pugliese G, Eades DM, Province MA, Sherman WR, Kilo C, and Williamson JR. Prevention of hemodynamic and vascular albumin filtration changes in diabetic rats by aldose reductase inhibitors. Diabetes 38: 1258-1270, 1989.

102. Tombran-Tink J, Chader GG, and Johnson LV. PEDF: A pigment epithelium-derived factor with potent neuronal differentiative activity. Exp Eye Res 53: 411-414, 1991.

103. Van den Enden MK, Nyengaard JR, Ostrow E, Burgan JH, and Williamson JR. Elevated glucose levels increase retinal glycolysis and sorbitol pathway metabolism. Implications for diabetic retinopathy. Invest Ophthalmol Vis Sci 36: 1675$1685,1995$.

104. Vincent JA and Mohr S. Inhibition of caspase-1/interleukin1beta signaling prevents degeneration of retinal capillaries in diabetes and galactosemia. Diabetes 56: 224-230, 2007.

105. Warboys CM, Toh HB, and Fraser PA. Role of NADPH oxidase in retinal microvascular permeability increase by RAGE activation. Invest Ophthalmol Vis Sci 50: 1319-1328, 2009.
106. Wild S, Roglic G, Green A, Sicree R, and King H. Global prevalence of diabetes: Estimates for the year 2000 and projections for 2030. Diabetes Care 27: 1047-1053, 2004.

107. Williamson JR, Chang K, Frangos M, Hasan KS, Ido Y, Kawamura T, Nyengaard JR, van den Enden M, Kilo C, and Tilton RG. Hyperglycemic pseudohypoxia and diabetic complications. Diabetes 42: 801-813, 1993.

108. Winkler BS, Arnold MJ, Brassell MA, and Sliter DR. Glucose dependence of glycolysis, hexose monophosphate shunt activity, energy status, and the polyol pathway in retinas isolated from normal (nondiabetic) rats. Invest Ophthalmol Vis Sci 38: 62-71, 1997.

109. Xie L, Zhu X, Hu Y, Li T, Gao Y, Shi Y, and Tang S. Mitochondrial DNA oxidative damage triggering mitochondrial dysfunction and apoptosis in high glucose-induced HRECs. Invest Ophthalmol Vis Sci 49: 4203-4209, 2008.

110. Yamagishi S, Nakamura K, Matsui T, Sato T, and Takeuchi M. Potential utility of statins, 3-hydroxy-3-methylglutaryl coenzyme A reductase inhibitors in diabetic retinopathy. Med Hypotheses 66: 1019-1021, 2006.

111. Yoh K, Hirayama A, Ishizaki K, Yamada A, Takeuchi M, Yamgishi S, Morito N, Nakano T, Ojima M, Shimohata H, Itoh K, Takahashi S, and Yamamoto M. Hyperglycemia induces oxidative and nitrosative stress and increases renal functional impairment in Nrf2-deficient mice. Genes Cells 13: 1159-1170, 2008.

112. Yoshida Y, Yamagishi S, Matsui T, Jinnouchi Y, Fukami K, Imaizumi T, and Yamakawa R. Protective role of pigment epithelium-derived factor (PEDF) in early phase of experimental diabetic retinopathy. Diabetes Metab Res Rev 25: 678686, 2009.

113. Zhang H. Scanning electron-microscopic study of corrosion casts on retinal and choroidal angioarchitecture in man and animals. Prog Ret Eye Res 13: 243-270, 1994.

114. Zheng Z, Chen H, Ke G, Fan Y, Zou H, Sun X, Gu Q, Xu X, and Ho PC. Protective effect of perindopril on diabetic retinopathy is associated with decreased vascular endothelial growth factor-to-pigment epithelium-derived factor ratio: Involvement of a mitochondria-reactive oxygen species pathway. Diabetes 58: 954-964, 2009.

115. Zheng Z, Chen H, Zhao H, Liu K, Luo D, Chen Y, Yang X, $\mathrm{Gu} Q$, and $\mathrm{Xu} X$. Inhibition of JAK2/STAT3-mediated VEGF upregulation under high glucose conditions by PEDF through a mitochondrial ROS pathway in vitro. Invest Ophthalmol Vis Sci 51: 64-71, 2010.

116. Zhou $Q$ and Liao JK. Pleiotropic effects of statins. Basic research and clinical perspectives. Circ I 74: 818-826, 2010.

Address correspondence to: Dr. David A. Antonetti University of Michigan Kellogg Eye Center 1000 Wall Street

Ann Arbor, MI 48105

E-mail: dantonet@umich.edu

Date of first submission to ARS Central, January 24, 2011; date of acceptance, February 5, 2011. 


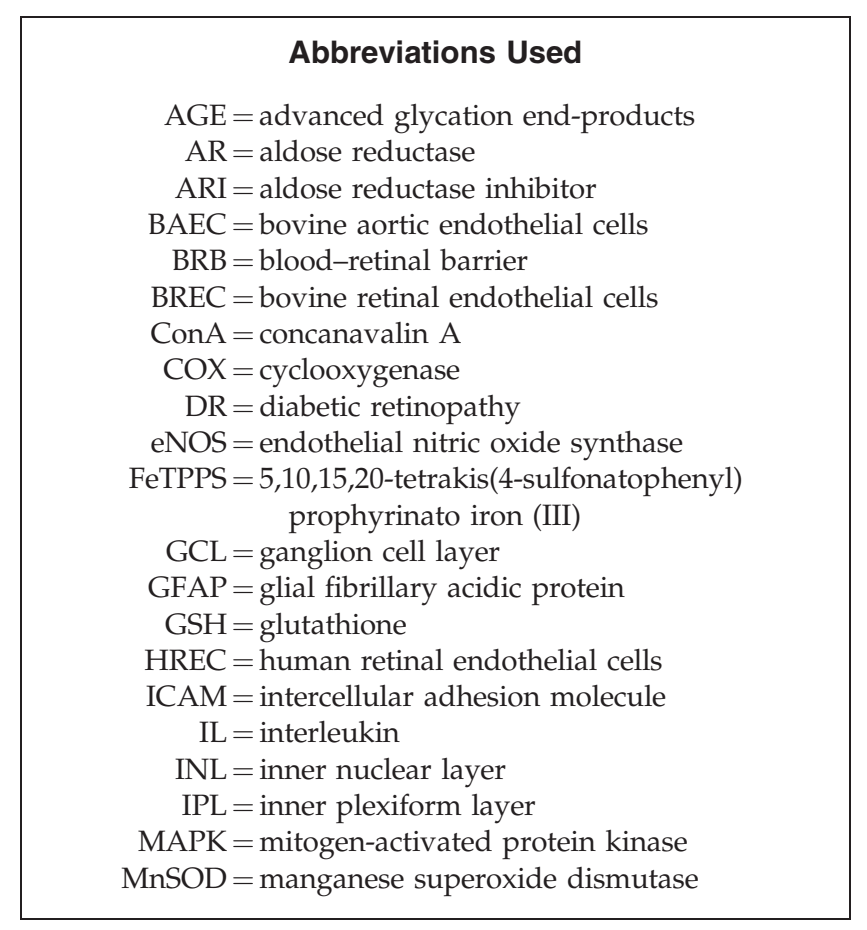

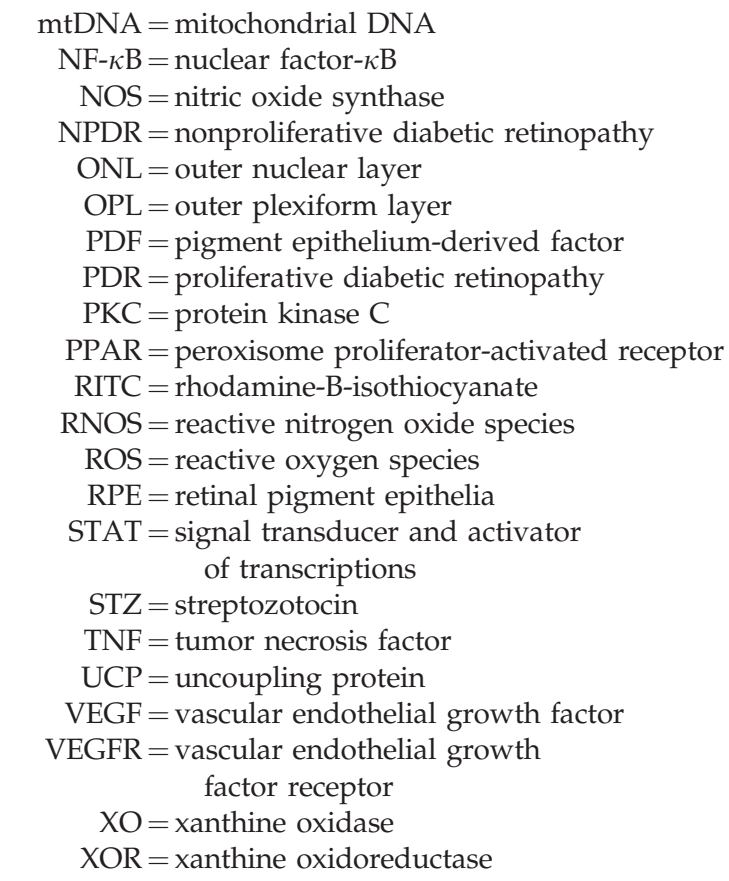




\section{This article has been cited by:}

1. Takhellambam S. Devi, Icksoo Lee, Maik Hüttemann, Ashok Kumar, Kwaku D. Nantwi, Lalit P. Singh. 2012. TXNIP Links Innate Host Defense Mechanisms to Oxidative Stress and Inflammation in Retinal Muller Glia under Chronic Hyperglycemia: Implications for Diabetic Retinopathy. Experimental Diabetes Research 2012, 1-19. [CrossRef]

2. Lorenza González-Mariscal, Miguel Quirós, Monica Díaz-Coránguez . ZO Proteins and Redox-Dependent Processes. Antioxidants \& Redox Signaling, ahead of print. [Abstract] [Full Text HTML] [Full Text PDF] [Full Text PDF with Links]

3. Ingolf E. Blasig, Reiner F. Haseloff . Tight Junctions and Tissue Barriers. Antioxidants \& Redox Signaling, ahead of print. [Abstract] [Full Text HTML] [Full Text PDF] [Full Text PDF with Links]

4. Caroline Coisne, Britta Engelhardt . Tight Junctions in Brain Barriers During Central Nervous System Inflammation. Antioxidants \& Redox Signaling, ahead of print. [Abstract] [Full Text HTML] [Full Text PDF] [Full Text PDF with Links]

5. Christine Lehner, Renate Gehwolf, Herbert Tempfer, Istvan Krizbai, Bernhard Hennig, Hans-Christian Bauer, Hannelore Bauer . Oxidative Stress and Blood-Brain Barrier Dysfunction Under Particular Consideration of Matrix Metalloproteinases. Antioxidants \& Redox Signaling, ahead of print. [Abstract] [Full Text HTML] [Full Text PDF] [Full Text PDF with Links]

6. Lena J. John, Michael Fromm, Jörg-Dieter Schulzke . Epithelial Barriers in Intestinal Inflammation. Antioxidants \& Redox Signaling, ahead of print. [Abstract] [Full Text HTML] [Full Text PDF] [Full Text PDF with Links]

7. Gianfranco Bazzoni . Pathobiology of Junctional Adhesion Molecules. Antioxidants \& Redox Signaling, ahead of print. [Abstract] [Full Text HTML] [Full Text PDF] [Full Text PDF with Links] 